Advances in Gene Technology: The Genome and Beyond -

Structural Biology for Medicine (Proceedings of the 2002 Miami

Nature Biotechnology Winter Symposium)

TheScientificWorld 2002, 2(S2), 132

ISSN 1532-2246; DOI 10.1100/tsw.2002.62

\title{
PROTEIN MISFOLDING AND HUMAN DISEASE
}

\author{
Christopher M. Dobson \\ Department of Chemistry, University of Cambridge, Lensfield Road, Cambridge CB2 1EW, U.K.
}

Protein folding is perhaps the most fundamental process associated with the generation of functional structures in biology. There has been considerable progress in the last few years in understanding the underlying principles that govern this highly complex process. Central to much of this progress has been the development of ideas as to the nature of the energy surface or landscape for a folding reaction. These ideas have arisen from a combination of theoretical analysis and experimental investigation[1]. Of particular importance in the latter has been the concerted application of a wide range of experimental techniques, each able to describe aspects of the structural changes taking place during the folding process. NMR spectroscopy and protein engineering have both been key methods in this approach because of their ability to provide structural and dynamical information at the level of individual residues. Recently, new approaches have been devised that combine experimental data directly with simulation techniques to define the structures of key species on the folding surface[2].

Recently, much research has also focused on the realisation that proteins can misfold in vivo and that this phenomenon is linked with a wide range of diseases, particularly those associated with modern highly developed societies. We have been investigating in particular the nature of the amyloidogenic diseases (that include Alzheimer's disease and the spongiform encephalopathies, e.g., BSE and CJD) in which protein misfolding leads to the aggregation of proteins, often into fibrillar or thread-like structures. We have looked in particular at a nonneuropathic amyloidosis associated with lysozyme, one of our model systems for investigating the fundamentals of protein folding[3]. This work has recently been extended by the finding that many proteins not asociated with clinical manifestations of disease can form amyloid structures in the laboratory under appropriately chosen conditions[4,5]. Such findings have led us to put forward ideas as to a common origin of the various diseases associated with the formation of amyloid structures. We have also speculated more generally that the avoidance of aggregation could be a significant driving force in the evolution of protein sequences and structures[6].

\section{REFERENCES}

1. $\quad$ Dinner, A.R. et al. (2000) Trends Biochem. Sci. 25, 331-339.

2. Vendruscolo, M. et al. (2001) Nature 409, 641-645.

3. $\quad$ Booth, D.R. et al. (1997) Nature 385, 787-793.

4. $\quad$ Chiti, F. et al. (1999) Proc. Natl. Acad. Sci. U. S. A. 96, 3590-3594.

5. Fandrich, M. et al. (2001) Nature 410, 165-166.

6. Dobson, C. (2001) Philos. Trans. R. Soc. London Ser. B 356, 133-145. 


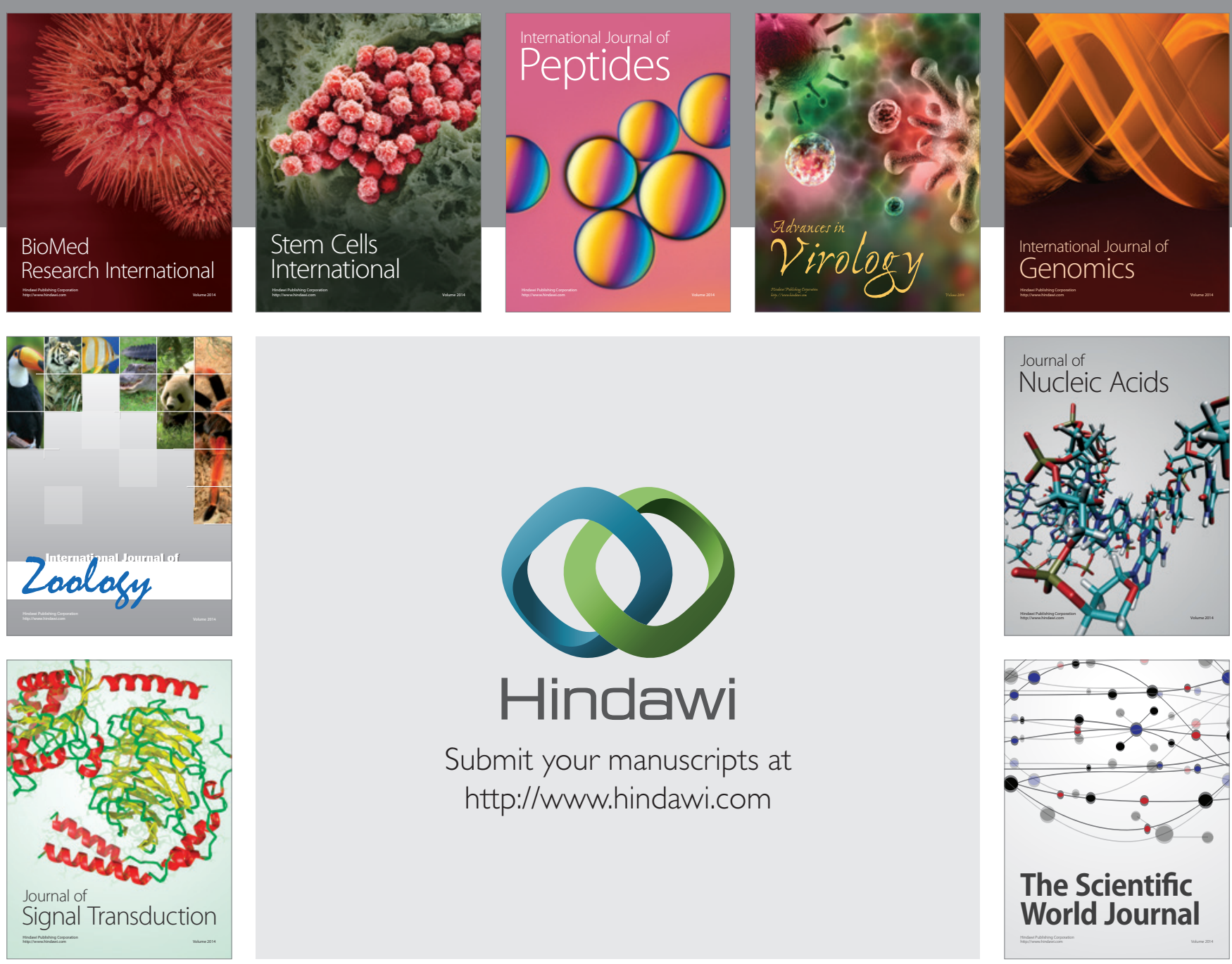

Submit your manuscripts at

http://www.hindawi.com
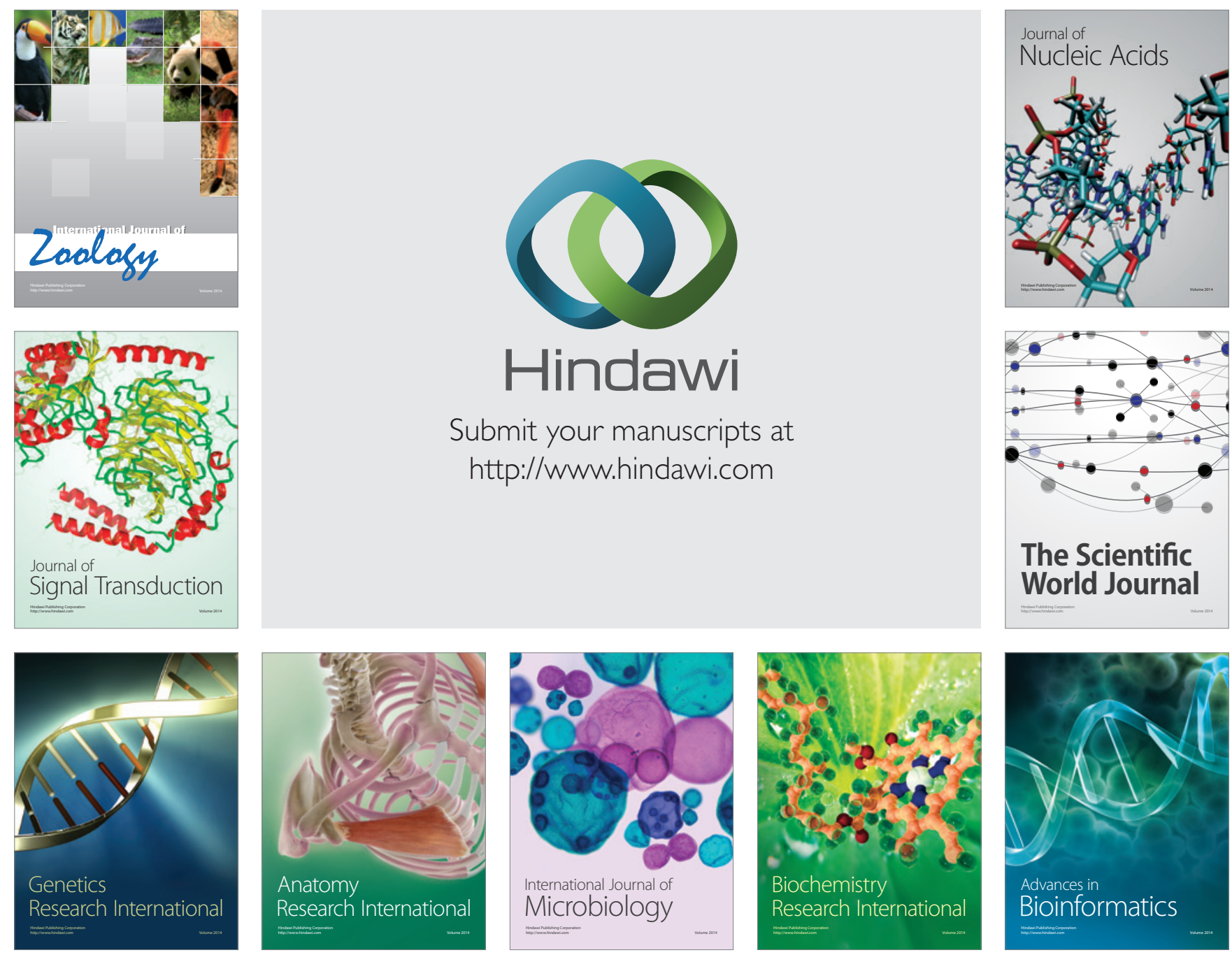

The Scientific World Journal
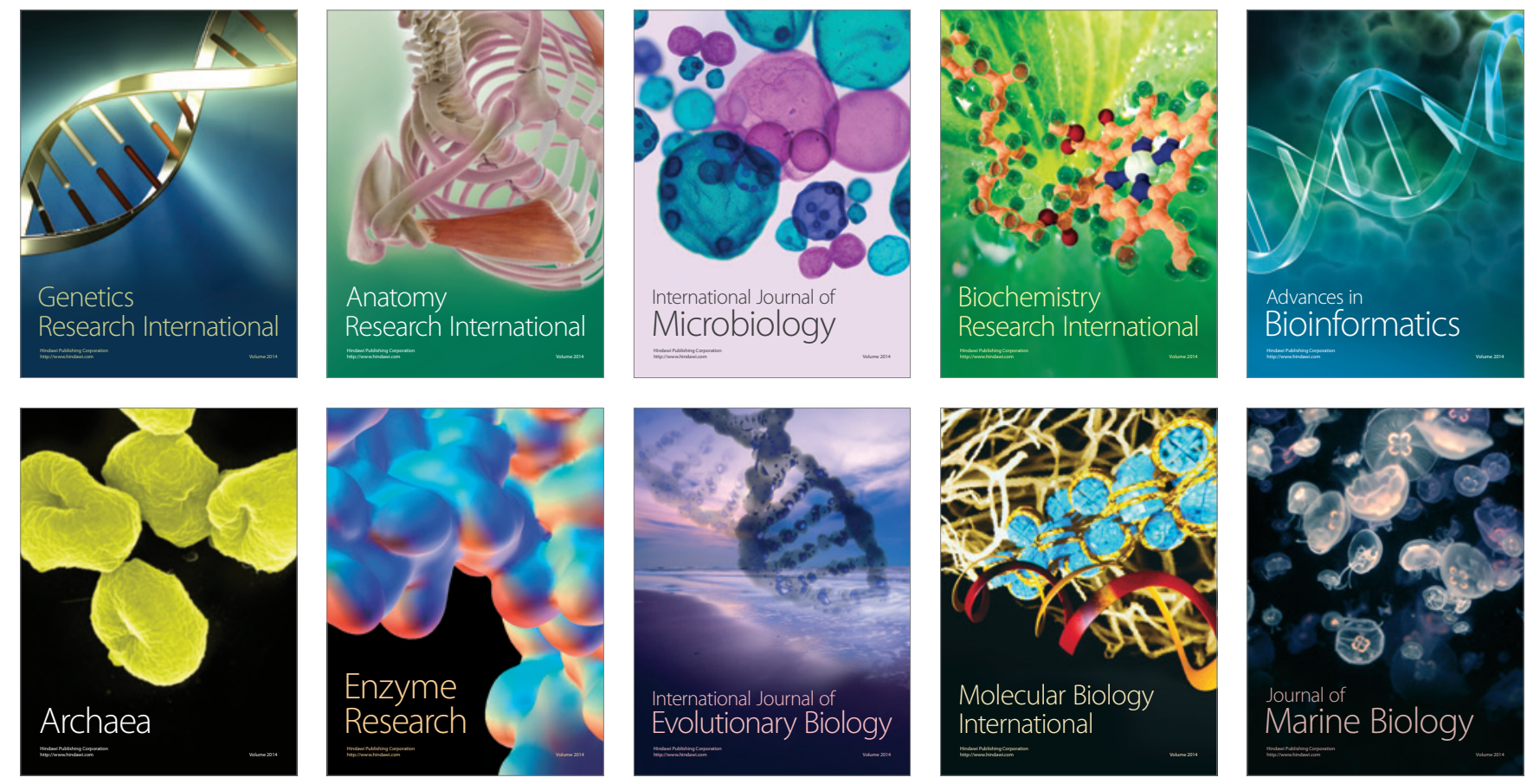